\title{
Is Transradial Access a Replacement Technique for Transfemoral Access in Neurointervention?
}

$\mathbf{T}$ ransradial access for neurointervention has experienced an explosion in interest over the past few years because of patient preferences, extrapolated cardiology data, and early studies supporting its use in the neurointerventional setting. As with any innovation, although there may be advantages, in the enthusiasm to include more tools in the armamentarium, the utility of the "tried and true" should not be forgotten.

As a backdrop, transradial access is newer than transfemoral, but it is not novel. The first cases on transradial intracranial neurointervention were published in 2003 and 2004, ${ }^{1,2}$ including aneurysm treatments in both anterior and posterior circulations, as well as spinal and dural fistula embolizations. This was preceded by a number of case series between 2000 and $2003,{ }^{2-5}$ which, together, demonstrated the use of transradial cerebral angiography since 1997 with an aggregated patient cohort in the hundreds. Techniques described then were similar to those used today, and the same difficulties were identified, including radial spasm, proximal vascular tortuosity ${ }^{3}$ and stenoses, ${ }^{4}$ limitations related to aortic arch branch morphology with resultant instability, ${ }^{5}$ some branches are clearly easier to access via one route, ${ }^{1}$ and learning curves. ${ }^{4}$ So, what has changed?

In the article published in this issue of the $A J N R$, we glean factors that may have pushed us toward this different technique. First, neurointerventions themselves are becoming more commonplace. This encourages attention to all aspects of neurointervention, including vascular access. Second, procedures requiring stronger antithrombotic regimens are increasingly performed, of which one is flow diversion. Hemorrhagic complications are known to be more common with transfemoral access, and this advantage of transradial access can be directly translated from the cardiology literature.

However, it is important to note in this study's recruitment period that only $51 \%(74 / 144)$ of cases were performed transradially. The reasons are not clearly stated, but one can imagine such variability may be because of a different pace of individual operators at the study centers adopting the transradial approach, or alternatively, case selection. Unless we know the rationale for the breakdown of transradial versus transfemoral access, the transradial complication and access conversion rates noted cannot be applied for a blanket "radial-first" strategy; these may only apply to the "radial appears preferable in this patient" strategy.

The influence of patient selection on complication rates may be more widespread in our literature. In the largest study comparing transradial versus transfemoral flow diversion to date, comprising 2285 patients, cases were drawn from preradial (2010-2015) and postradial (2016-2019) eras. Regarding the postradial era, the authors note ". . . access approach was determined by the attending neurointerventionalist . . . based on operator expertise and patient-specific considerations." Comparing 2151 transfemoral versus 134 transradial interventions recruited between 2010 and 2019 necessitates inclusion of cases (performed transfemorally) that would have been more optimally performed transradially. Against not having options other than transfemoral access, subsequent selection of suitable patients for transradial access should render better outcomes in both groups because these cases would have been more appropriate for transradial access in the first place. The relatively low numbers of transradial access cases (versus transfemoral) also suggest that patients were very highly selected for suitability.

$\mathrm{Li}$ et al's ${ }^{6}$ argument against this is the lack of change in the transfemoral overall complication rates between their preradial (2010-2015) and postradial (2016-2019) eras, but this raises a bigger question: Why were transfemoral complication rates not falling, especially when predominantly 1 device (99.2\%) was used, experience was growing, and presumably in the postradial era, cases less suitable for transfemoral access were being taken away for a transradial approach? Were cases with more challenging intracranial anatomy being attempted predominantly transfemorally? Unfortunately, the provided demographics pertaining to aneurysm location do not provide adequate information.

There are too many potential biases here to make a definite answer possible, and perhaps the only way to comprehensively prove this would be to randomize. This may prove that radial access is truly preferable, at least in most nonselected cases, for the average operator. Alternatively, it may be useful to retrospectively analyze aortic arch and branch characteristics in a semiquantitative fashion between the 2 access techniques. Until then, 
utter adherence to always attempting a radial-first strategy may, similar to only performing transfemoral access, render overall higher complication and access conversion rates. The difficulty here is we do not know how much more exactly, but an earlier study by Chen et $\mathrm{al}^{7}$ suggests it may be as high as $20.4 \%$.

As an analogy, there would presumably be little argument that transfemorally accessing a bovine left carotid using a Simmons catheter renders a somewhat higher difficulty and risk than using a right transradial approach (or transfemorally accessing a left carotid in a young, nonbovine patient). How much more is the question, and it may be that in the hands of an experienced operator, the difference in risk is negligible. It is thus fair to say that as individual experience with transradial approach increases, anatomic access-related risk may decrease, making the hemorrhagic risks of transfemoral access more prominent in the risk-benefit calculation. But this equipoise calculation may remain very individual.

Thus, the emphasis here is on the value of individualization, and the authors have commendably added to the important conversation regarding what constitutes favorable anatomy for transradial access. Previous papers have identified factors that favor radial access, such as anticoagulation, obesity, femoral artery atheroma, type 3 and bovine arch, ${ }^{8}$ and narrow-angle ${ }^{7}$ or parallel morphology of the brachiocephalic and left common carotid artery, ${ }^{9}$ perhaps especially if they angulate toward the ascending or the descending aorta. However, the current article usefully takes these further, including specifics of aortic branch anatomy, with imaging. Such factors play into the safety of transradial versus transfemoral access, and these cannot be translated from the cardiology literature, as the arch, and obviously the carotid and vertebral arteries, are not accessed in the same fashion in coronary intervention compared with neurointervention.

It is also important to note that the current generation of guide catheters used in transradial neurointervention was not designed for this usage. Although they have performed well, it is conceivable that complication rates and specific difficulties experienced with the current generation of devices may not be applicable in the future. There needs to be ongoing review of the balance of safety between transradial and transfemoral intervention, especially as experience in transradial intervention and the scope of its utilization grows.

Lastly, although the need for flow diverter deployment systems to use larger bore guide catheters and larger loading forces was raised as a reason for making specific comparison between transradial and transfemoral access, $6 \mathrm{~F}$ systems can perhaps be considered the standard in many centers for a multitude of more complex neurointerventional operations, such as stent-assisted coil embolization and endosaccular flow disruption. In tortuous vascular systems, a transradial approach for these cases would raise similar concerns. It is perhaps the aggregate stiffness and bulk of the device systems delivered, after arch anatomy and appropriateness of catheter systems, that poses the next most important factor to suitability. One such procedure is transradial carotid stent placement. Although sometimes older systems have been repurposed satisfactorily for use in some cases (eg, Preformed Simmons Envoy XB catheters, Codman Neuro), it may be in this literature that we will glean the newest information regarding the actual, coal face applicability of improvements in catheter technology.

Perhaps the advent of mainstream transradial neurointervention can be thought of not as the succession of transfemoral access but as the opening of a door to more options resulting in better care of the patient, similar to the advent of flow diversion itself. There will always be practitioners who will prefer flow diverter techniques because of training or practice patterns. Transradial access is similar, and it is likely that transradial access will play a growing role in neurointervention. However, it is important that continued practice and training of future neurointerventionists maintain the ability for practitioners to use multiple alternatives so that patients who are at increased risk of transfemoral complications can be offered "radial first," and those with unfavorable arch profiles can be offered "femoral first" - that is, a patient-tailored strategy.

\section{REFERENCES}

1. Nohara AM, Kallmes DF. Transradial cerebral angiography: technique and outcomes. AJNR Am J Neuroradiol 2003;24:1247-50 Medline

2. Schönholz C, Nanda A, Rodríguez J, et al. Transradial approach to coil embolization of an intracranial aneurysm. J Endovasc Ther 2004;11: 411-13 CrossRef Medline

3. Matsumoto Y, Hokama M, Nagashima H, et al. Transradial approach for selective cerebral angiography: technical note. Neurol Res 2000; 22:605-08 CrossRef Medline

4. Matsumoto $\mathrm{Y}$, Hongo K, Toriyama T, et al. Transradial approach for diagnostic selective cerebral angiography: results of a consecutive series of 166 cases. AJNR Am J Neuroradiol 2001;22:704-08 Medline

5. Levy EI, Boulos AS, Fessler RD, et al. Transradial cerebral angiography: an alternative route. Neurosurgery 2002;51:335-42 CrossRef Medline

6. Li Y, Chen SH, Spiotta AM, et al. Lower complication rates associated with transradial versus transfemoral flow diverting stent placement. $J$ Neurointervent Surg 2020 Jun 2. [Epub ahead of print] CrossRef Medline

7. Chen SH, Snelling BM, Shah SS, et al. Transradial approach for flow diversion treatment of cerebral aneurysms: a multicenter study. J Neurointervent Surg 2019;11:796-800 CrossRef Medline

8. Snelling BM, Sur S, Shah SS, et al. Transradial cerebral angiography: techniques and outcomes. J NeuroIntervent Surg 2018;10:87481 CrossRef Medline

9. Waqas M, Vakharia K, Dossani RH, et al. Transradial access for flow diversion of intracranial aneurysms: case series. Interv Neuroradiol 2020 Jul 5. [Epub ahead of print] CrossRef Medline

(1) A.H. Chiu

Neurological Intervention \& Imaging Service of Western Australia, Sir Charles Gairdner, Royal Perth and Fiona Stanley Hospitals, WA Health; Internal Medicine, University of Western Australia; and UWA Centre for Medical Research, University of Western Australia, Perth, Australia http://dx.doi.org/10.3174/ajnr.A6935 